\title{
Increased expression of RBMS3 predicts a favorable prognosis in human gallbladder carcinoma
}

\author{
YOULIANG WU ${ }^{1 *}$, DELONG MENG ${ }^{2 *}$, YEXIANG YOU ${ }^{1}$, RUOCHUAN SUN $^{1}$, QIANG YAN ${ }^{1}$, \\ JUNJUN BAO $^{1}$, YANJUN SUN ${ }^{3}$, DAPENG YUN ${ }^{4}$, YONGXIANG LI ${ }^{1}$ and DENGQUN SUN ${ }^{3}$ \\ ${ }^{1}$ Department of General Surgery, The First Affiliated Hospital of Anhui Medical University,
} Hefei, Anhui 230022, P.R. China; ${ }^{2}$ Department of Molecular Biology, The University of Texas Southwestern Medical Center, Dallas, TX 75390, USA; ${ }^{3}$ Department of General Surgery, The Armed Police Corps Hospital of Anhui, Hefei, Anhui 230041, P.R. China; ${ }^{4}$ Department of Pharmacology, The University of Texas Southwestern Medical Center, Dallas, TX 75390, USA

Received October 27, 2019; Accepted March 22, 2020

DOI: 10.3892/or.2020.7594

\begin{abstract}
Multiple regions in the short arm of chromosome 3 are frequently deleted in a variety of solid tumors including gallbladder carcinoma (GBC). RNA binding motif, single-stranded interacting protein 3 (RBMS3), a tumor suppressor gene (TSG), is located in this region. However, the role of RBMS3 in GBC remains unclear. Reverse transcription-quantitative polymerase chain reaction (RT-qPCR) and western blotting were performed to evaluate the mRNA and protein expression levels of RBMS3 in 41 fresh frozen GBC tissues and paired normal tissues. An immunohistochemical assay was performed on a tissue microarray (TMA, consisting of 125 cases GBC and 47 normal controls). Microvessel density (MVD) counts were determined using CD34 immunohistochemical staining. Moreover, univariate and multivariate analyses were performed to determine the correlations between RBMS3 expression, MVD and patient prognosis. Cellular functions including proliferation, clonogenicity and apoptosis, were assessed to further identify in vitro roles of RBMS3. It was revealed that both mRNA and protein expression levels of RBMS3 were significantly lower in GBC tissues than in normal controls. Multivariate Cox regression analyses demonstrated cytoplasmic RBMS3 expression as an independent prognostic factor correlated with GBC angiogenesis, histo-
\end{abstract}

Correspondence to: Professor Dengqun Sun, Department of General Surgery, The Armed Police Corps Hospital of Anhui, Hefei, Anhui 230041, P.R. China

E-mail: sundengqunsyl@126.com

Professor Yongxiang Li, Department of General Surgery, The First Affiliated Hospital of Anhui Medical University, Hefei, Anhui 230022, P.R. China

E-mail: yongxiangli_1@hotmail.com

*Contributed equally

Key words: gallbladder carcinoma, RBMS3, tumor suppressor gene, MVD, prognostic marker pathological differentiation and TNM stage. Kaplan-Meier curves revealed that patients with lower cytoplasmic RBMS3 levels had a significantly worse OS than patients with higher cytoplasmic RBMS3 expression. Additionally, ectopic expression of RBMS3 markedly suppressed GBC cell proliferation and clonogenicity and promoted apoptosis in vitro. These findings indicated the potential of cytoplasmic RBMS3 as a tumor prognostic biomarker and a promising therapeutic target for GBC.

\section{Introduction}

Gallbladder carcinoma (GBC) is the most aggressive and prevalent malignant tumor in the biliary tract (1). With a lack of effective early molecular biomarkers, most GBC patients have a poor prognosis due to delayed diagnosis in advanced stages (2). Therefore, it is imperative to identify additional valuable molecular prognostic biomarkers for GBC.

Chromosomal deletion is a common mechanism of the inactivation of tumor suppressor genes (TSGs) (3). The deletion of multiple regions on the short arm of chromosome 3 (3p) represents a genetic alteration hotspot in numerous human solid tumors including GBC (4-7), suggesting the existence of one or more TSGs in this region. One such gene located at 3p24-p23, namely RNA binding motif, single-stranded interacting protein 3 (RBMS3) is a member of the c-Myc gene single-strand binding protein (MSSP) family and encodes an RNA-binding protein (8). The MSSP family members have numerous diverse functions, and by cooperating with the c-Myc protein, regulate processes such as DNA replication, gene expression, cell cycle progression, cell proliferation and induction of apoptosis $(9,10)$. It has been reported in esophageal squamous cell carcinoma (ESCC) that RBMS3 can arrest the cell cycle at the G1/S checkpoint by directly binding to the promoter region of c-Myc (11). Conversely, the RBMS3 protein has also been suggested to be located in the cytoplasm, indicating a potential cytoplasmic function of RNA metabolism control rather than transcription $(8,12)$. Recent studies demonstrated that RBMS3 may act as a TSG in several types of solid tumors (11-14). Downregulation of RBMS3 mRNA and protein has been detected in gastric cancer (GC), 
nasopharyngeal carcinoma (NPC) and lung squamous cell carcinoma (LSCC). In addition, downregulation of RBMS3 in GC, LSCC, NPC and ESCC has been revealed to be strongly associated with worse outcomes $(11,12,14,15)$. Overexpression of RBMS3 effectively suppressed ESCC cell growth, colony formation and tumor formation in nude mice (11). RBMS3 has also been reported to inhibit angiogenesis, a necessary nutrient supply strategy for most solid tumors, by negatively regulating of MMP2, MMP-9, VEGF and $\beta$-catenin to inhibit tumor growth $(12,15)$. However, its expression and role in human GBC remains unclear. Therefore, the present study was conducted to address these topics.

In the present study, RT-qPCR, western blotting and immunohistochemistry (IHC) were utilized to characterize the expression levels of RBMS3 in GBC tissues. The association of RBMS3 expression with clinicopathological parameters and prognosis was analyzed, and the relationship between RBMS3 expression and microvascular density (MVD) was investigated. Moreover, the role of RBMS3 in GBC proliferation, clonogenicity and apoptosis in vitro was determined.

\section{Materials and methods}

Patients and tissue specimens. To construct the tissue microarray (TMA), a total of 125 formalin-fixed, paraffin-embedded GBC and 47 randomly selected normal gallbladder tissues were collected at the Department of General Surgical of the Armed Police Corps Hospital of Anhui (Hefei, China) from December 2004 to December 2014. To obtain the complete clinical information, all patients were followed-up regularly every 2 months during the first 2 years post-surgery and every 6 months afterwards. Complete clinical follow-up was updated until December 2016. Immunohistochemical staining and patient pathological characteristics were reviewed by two experienced pathologists. Tumor node metastasis (TNM) staging was classified based on the 7th edition of TNM classification criteria published by the American Joint Committee on Cancer (AJCC) in 2010. Detailed clinicopathological parameters are described in Table I. In detail, the overall cohort consisted of 34 males and 91 females with a mean age of 66.58 years and a median age of 68 years (range, 35 to 93 years). Additionally, 41 pairs of matched fresh GBC tissues and adjacent non-tumor tissues (at least $5 \mathrm{~cm}$ from the tumor edge) were collected, snap-frozen in liquid nitrogen and stored at $-80^{\circ} \mathrm{C}$ between May 2015 and August 2017, until use in RT-qPCR and western blot analysis to compare the protein and mRNA expression levels of RBMS3 between GBC and adjacent non-tumor tissues. All diagnoses were histopathologically confirmed. None of the patients had undergone any anticancer treatment prior to surgery. The present study was approved by the Institute Research Ethics Committee of the Armed Police Corps Hospital of Anhui and written informed consent was obtained from all patients involved.

$R N A$ preparation and reverse transcription-quantitative polymerase chain reaction ( $R T-q P C R)$. Total RNA was isolated from freshly frozen tissues using TRIzol reagent (Invitrogen; Thermo Fisher Scientific) and reverse-transcribed (RT) to generate first-strand cDNA using ReverTra Ace qPCR RT Master Mix (Toyobo Life Science) according to the protocol supplied by the manufacturer. The PCR primers used for amplification were as follows: RBMS3 forward, 5'-GGT AGCATCTCTCAAGGCAAAT-3' and reverse, 5'-CATGTC CAAAGGGTTTCAGCA-3'; and glyceraldehyde-3-phosphate dehydrogenase (GAPDH), which was used as the internal control: Forward, 5'-ATCAAGAAGGTGGTGAAGCAGG-3', and reverse, 5'-CGTCAAAGGTGGAGGAGTGG-3'. qPCR was carried out on an ABI Prism 7900 HT Sequence Detection System (Applied Biosystems; Thermo Fisher Scientific, Inc.) using a SYBR Green mix (Toyobo Life Science). The amplification of the target sequence was performed in a $10-\mu l$ reaction system with the following conditions: Denaturation $\left(95^{\circ} \mathrm{C}\right.$ for $5 \mathrm{~min})$ and 40 cycles of amplification and quantification $\left(95^{\circ} \mathrm{C}\right.$ for $15 \mathrm{sec}$ and $60^{\circ} \mathrm{C}$ for $45 \mathrm{sec}$ ). Each sample was detected in triplicate, and a melting curve was analyzed to confirm the amplification specificity. The results of relative mRNA expression were calculated using the $2^{-\Delta \Delta \mathrm{Ca}}$ method (16).

Protein extraction and western blotting. Western blotting was performed as described previously $(17,18)$. Briefly, total proteins were extracted from fresh frozen tissues by RIPA lysis buffer (product code P0013B; Beyotime Institute of Biotechnology). Protein concentrations were determined using the BCA Protein Assay Kit (Beyotime Institute of Biotechnology). Protein samples $(30 \mu \mathrm{g})$ were then separated electrophoretically using $10 \%$ sodium dodecyl sulfate-polyacrylamide (SDS-PAGE) gels and transferred to nitrocellulose membranes (EMD Millipore). After blocking the nonspecific binding sites with 5\% nonfat milk diluted in Tris-buffered saline with Tween-20 (TBST) for $1 \mathrm{~h}$ at room temperature, the membranes were blotted with a rabbit polyclonal anti-RBMS3 antibody (1:2,000; product code ab198248; Abcam) at $4^{\circ} \mathrm{C}$ overnight. After three 10-min TBST washes, the membranes were blotted with horseradish peroxidase-labeled anti-rabbit IgG secondary antibody (product no. 7074P2; Cell Signaling Technology) at a dilution of 1:3,000 at room temperature for $60 \mathrm{~min}$. The membranes were then washed three times with TBST for $10 \mathrm{~min}$ each time, and the bound antibodies were developed using the enhanced chemiluminescence system (product code 34577; Thermo Fisher Scientific, Inc.). GAPDH was detected as a loading control using an anti-GAPDH antibody (1:3,000; Ab103-02; Vazyme).

IHC and scoring. The immunohistochemical assay was performed as previously described $(19,20)$. Briefly, H\&E-stained slides were screened to identify optimal intratumoral tissue to construct a TMA (Shanghai Biochip Company, Ltd.) before IHC. Multiple $4-\mu \mathrm{m}$-thick sections were prepared with a microtome and incubated at $63^{\circ} \mathrm{C}$ for $1 \mathrm{~h}$, deparaffinized using xylene, and rehydrated in a graded ethanol series. Heat-induced antigen retrieval was performed at $100^{\circ} \mathrm{C}$ for $10 \mathrm{~min}$ in citrate buffer ( $\mathrm{pH}$ 6.0). The sections were then treated with $3 \%$ hydrogen peroxide in methanol and $1 \%$ bovine serum albumin to quench endogenous peroxidase activity and to block nonspecific staining. Subsequently, the sections were incubated with primary antibodies against RBMS3 (1:50; product code ab198248; Abcam) and CD34 (1:1,000; product code ab81289, Abcam) overnight at $4^{\circ} \mathrm{C}$ followed by a PBS wash. The sections were then incubated at room temperature for $30 \mathrm{~min}$ with horseradish peroxidase-labeled anti-rabbit 
Table I. Clinical and pathological features of the GBC patients $(n=125)$.

\begin{tabular}{|c|c|}
\hline Clinicopathological variables & No. of patients $(\%)$ \\
\hline \multicolumn{2}{|l|}{ Sex } \\
\hline Male & $34(27.2)$ \\
\hline Female & $91(72.8)$ \\
\hline \multicolumn{2}{|l|}{ Age (years) } \\
\hline$<68$ & $58(46.4)$ \\
\hline$\geq 68$ & $67(53.6)$ \\
\hline \multicolumn{2}{|l|}{ Tumor size (cm) } \\
\hline$<2$ & $60(48)$ \\
\hline$\geq 2$ & $65(52)$ \\
\hline \multicolumn{2}{|l|}{ Differentiation } \\
\hline High/moderate & $80(64)$ \\
\hline Low/undifferentiated & $45(36)$ \\
\hline \multicolumn{2}{|l|}{ Depth of invasion } \\
\hline $\mathrm{T} 1 / \mathrm{T} 2$ & $37(29.6)$ \\
\hline $\mathrm{T} 3 / \mathrm{T} 4$ & $88(70.4)$ \\
\hline \multicolumn{2}{|l|}{ Lymph node metastasis } \\
\hline Yes & $51(40.8)$ \\
\hline No & $74(59.2)$ \\
\hline \multicolumn{2}{|l|}{ TNM } \\
\hline $\mathrm{I} / \mathrm{II}$ & $81(64.8)$ \\
\hline III/IV & $44(35.2)$ \\
\hline \multicolumn{2}{|l|}{ Gallstones } \\
\hline Yes & $83(66.4)$ \\
\hline No & $42(33.6)$ \\
\hline \multicolumn{2}{|l|}{$\mathrm{AFP}(\mu \mathrm{g} / \mathrm{l})$} \\
\hline$<20$ & $120(96)$ \\
\hline$\geq 20$ & $5(4)$ \\
\hline \multicolumn{2}{|l|}{ CEA (ng/ml) } \\
\hline$<5$ & $99(79.2)$ \\
\hline$\geq 5$ & $26(20.8)$ \\
\hline \multicolumn{2}{|l|}{ CA199 (U/ml) } \\
\hline$<37$ & $81(64.8)$ \\
\hline$\geq 37$ & $44(35.2)$ \\
\hline
\end{tabular}

GBC, gallbladder carcinoma; TNM, tumor-node-metastasis; AFP, alpha fetoprotein; CEA, carcino-embryonic antigen; CA199, carbohydrate antigen 199.

IgG secondary antibody (product code K8002; Dako), PBS washed and visualized using an autostainer link instrument (product code Autostainer Link 48; Dako) according to the manufacturer's instructions. For negative controls, the primary antibodies were substituted with normal rabbit IgG (product code A7016; Beyotime Institute of Biotechnology). The immunohistochemical staining results were assessed by two independent pathologists who were blinded to the patient clinical data according to the proportion of positive cells and the staining intensity. The staining 'percentage' (percentage scores) were graded using four categories: 0 for no cells stained,
1 for $<25 \%, 2$ for $25-75 \%$, and 3 for $>75 \%$ of cells stained. The 'intensity' measurements (intensity score) were divided into four groups: 0 for negative, 1 for weak, 2 for moderate and 3 for strong. The immunoreactivity score (IRS) was defined by the 'percentage $\mathrm{x}$ intensity'. Specimens were scored as follows: Negative (IRS $=\sim 0-2)$, positive (IRS $=\sim 3-9$ ).

MVD counting. The MVD was counted by two independent pathologists without knowledge of the patient data. Microvessels were evaluated by counting CD34-stained endothelial cells according to the generally accepted criteria developed by Weidner et al (21). Any immunostained endothelial cell or endothelial cell cluster that was clearly separate from other nearby microvessels could be considered a countable microvessel. Vessels with vessel wall thickness $>2.75 \mu \mathrm{m}$ or with thick muscular walls were excluded. Immunostained sections were initially scanned at a low power (magnification, x100) under a light microscope (Leica Microsystems $\mathrm{GmbH}$ ) to identify 'hot spots', defined as areas with the highest number of microvessels. Three representative areas of 'hot spots' were then counted under a high-power (magnification, x200) microscope. The final MVD count was determined as the mean value of the three sections examined.

Cell culture and lentivirus infection. Two human GBC cell lines (GBC-SD and SGC996) and the human embryonic kidney cell line $293 \mathrm{~T}$ were purchased from Shanghai GeneChem Co., Ltd. These cell lines were cultured in RPMI-1640 medium (Gibco; Thermo Fisher Scientific, Inc.) supplemented with $10 \%$ fetal bovine serum (FBS; Gibco; Thermo Fisher Scientific, Inc.), penicillin (100 U/ml) and streptomycin $(100 \mu \mathrm{g} / \mathrm{ml})$, at $37^{\circ} \mathrm{C}$ in a humidified incubator containing $5 \% \mathrm{CO}_{2}$. The lentiviral overexpression vector RBMS3 GV365 (OE, Ubi-RBMS3-3FLAG-CMV-EGFP) and the corresponding negative control GV365 vector (NC, Ubi-MCS-3FLAG-CMV-EGFP) were purchased from Shanghai GeneChem Co., Ltd. The packaging procedures and infection of lentiviruses were performed according to a previous study (22). The overexpression efficacy of target genes was detected by western blot analysis.

Cell proliferation assay and clonogenic assay. Cell proliferation and colony formation were assessed to evaluate the role of RBMS3 on the proliferation capabilities of GBC cells. Briefly, for the cell proliferation assay previously described (23), RBMS3 overexpression (OE) and vector control (NC) cells were seeded into 96-well plates $(2,000$ cells/well) in sextuplicate and cell proliferation was assessed using Cell Counting Kit-8 (CCK-8; Sigma-Aldrich; Merck KGaA) assay at different time-points according to the manufacturer's instructions. The absorbance was determined at $450 \mathrm{~nm}$ using a Universal Microplate Reader (BioTek Instruments, Inc.). In short, the clonogenic assay was performed as previously described (24), whereby the RBMS3 overexpressing and vector control cells $(\sim 800$ cells/well) were plated into 6 -well plates and the medium was replaced every three days. Two weeks later, the surviving colonies were fixed by $4 \%$ polyoxymethylene at room temperature for $30 \mathrm{~min}$, and stained with Giemsa, and colonies ( $>50$ cells/colony) were then counted. Each assay was performed at least three times. 
Table II. The expression of RBMS3 in GBC and normal tissues.

\begin{tabular}{lcccc}
\hline Groups & $\begin{array}{c}\text { Nuclear RBMS3- } \\
\text { positive/cytoplasmic } \\
\text { RBMS3-positive }\end{array}$ & $\begin{array}{c}\text { Nuclear RBMS3- } \\
\text { positive/cytoplasmic } \\
\text { RBMS3-negative }\end{array}$ & $\begin{array}{c}\text { Nuclear RBMS3- } \\
\text { negative/cytoplasmic } \\
\text { RBMS3-positive }\end{array}$ & $\begin{array}{c}\text { Nuclear RBMS3- } \\
\text { negative/cytoplasmic } \\
\text { RBMS3-negative }\end{array}$ \\
\hline GBC tissues & $1 / 125(0.8)$ & $4 / 125(3.2)$ & $46 / 125(36.8)$ & $74 / 125(59.2)$ \\
normal tissues & $5 / 47(10.6)$ & $3 / 47(6.4)$ & $24 / 47(51.1)$ & $15 / 47(31.9)$ \\
P-value & $\mathbf{0 . 0 0 8}$ & 0.611 & 0.09 & $\mathbf{0 . 0 0 1}$ \\
\hline
\end{tabular}

$\mathrm{P}<0.05$ was defined as statistically significant and is indicated in bold. RNA binding motif, single-stranded interacting protein 3; GBC, gallbladder carcinoma.
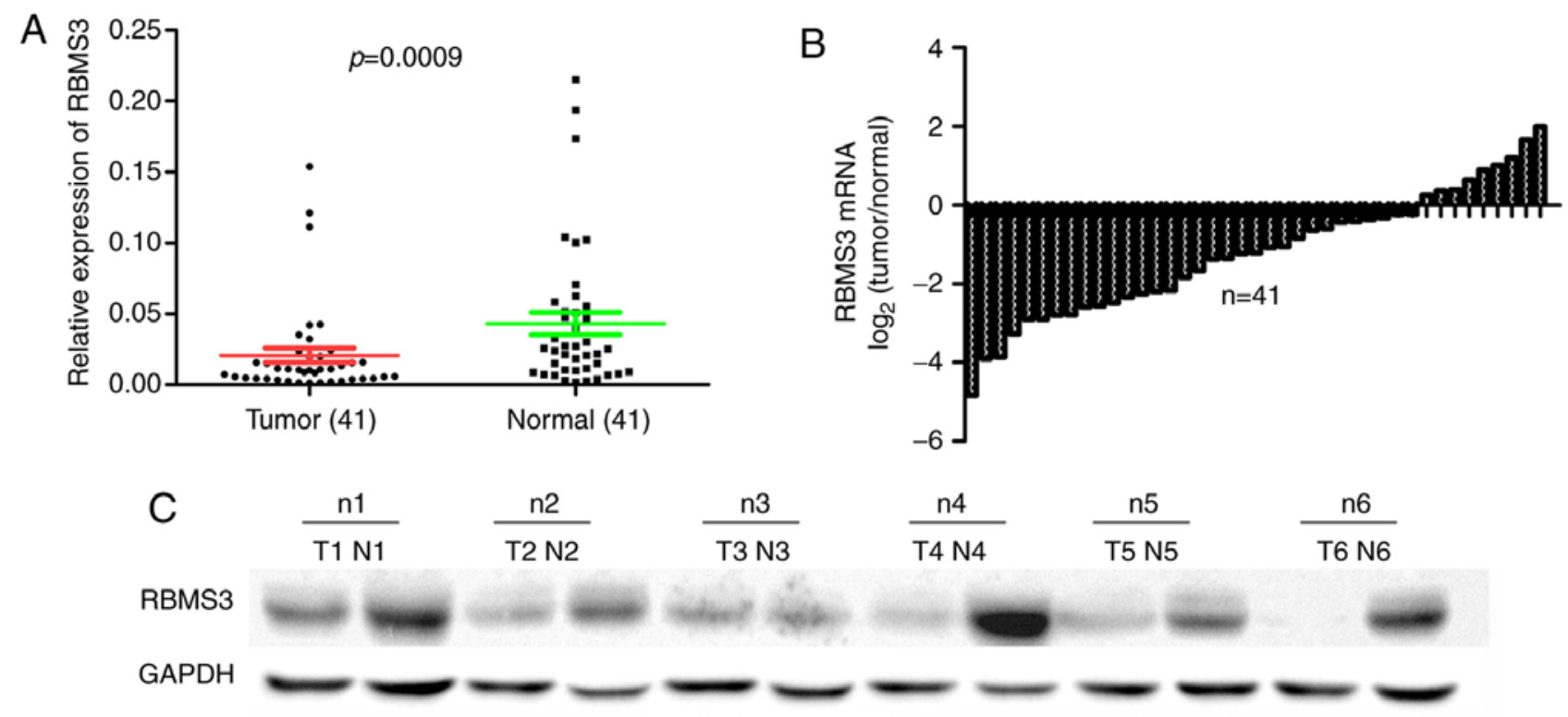

Figure 1. mRNA and protein expression levels of RBMS3 in clinical samples. (A) Scatter plots of the relative expression of RBMS3 mRNA in tumors and normal tissues. (B) Bar plots of RBMS3 mRNA expression in GBC tissues compared with normal tissues. Data for each patient is presented as the $\log _{2}$ ratio of tumor tissue/normal tissue. (C) The protein expression level of RBMS3 was analyzed by western blot assay. Representative protein expression level of RBMS3 in 6 pairs of tumor samples (T) and corresponding normal controls (N). GAPDH was used as an endogenous control. RBMS3, RNA binding motif, single-stranded interacting protein 3; GBC, gallbladder carcinoma.

Apoptosis assay. Apoptosis of the GBC-SD and SGC996 cells was analyzed using the APC-conjugated Annexin V (Annexin V-APC; eBioscience; Thermo Fisher Scientific, Inc.) kit according to the manufacturer's instructions. The percentage of apoptotic cells was analyzed by flow cytometry (FACSCalibur; BD Biosciences). The detailed apoptosis analysis is described in a previous study (25).

Statistical analysis. All statistical analyses were performed using SPSS 16.0 software (SPSS, Inc.). The associations between RBMS3 expression and clinicopathological characteristics were analyzed by chi-square tests. A paired-samples t-test was used to compare the RBMS3 mRNA levels between freshly frozen GBC and paired normal tissues. The overall survival (OS) analysis was performed by the Kaplan-Meier method, and statistical significance was analyzed using the log-rank test. Cox regression analysis was used to estimate the independent risk factor for OS of GBC patients after surgery. Differences between two groups for in vitro studies were assessed using Student's t-test. All statistical tests were two-sided, with P-values $<0.05$ considered to indicate a statistically significant difference. $\left({ }^{*} \mathrm{P}<0.05,{ }^{* *} \mathrm{P}<0.01,{ }^{* * *} \mathrm{P}<0.001\right.$ and ${ }^{\#} \mathrm{P}<0.0001$, respectively, as indicated in the figures and legends).

\section{Results}

Expression of RBMS3 $m R N A$ and protein in matched fresh $G B C$ tissues and adjacent non-tumor tissues. Low expression of RBMS3 has been reported in certain human cancers (12). However, the expression of RBMS3 in GBC has not been investigated. To determine the expression of RBMS3 in GBC tissues, the mRNA and protein expression levels of RBMS3 in a cohort of 41 GBCs and paired adjacent non-tumor tissue specimens were assessed by RT-qPCR and western blot analysis. The results revealed that the mean expression level of RBMS3 mRNA in GBC tissues $(0.021 \pm 0.033$, normalized to GAPDH gene expression) 
A

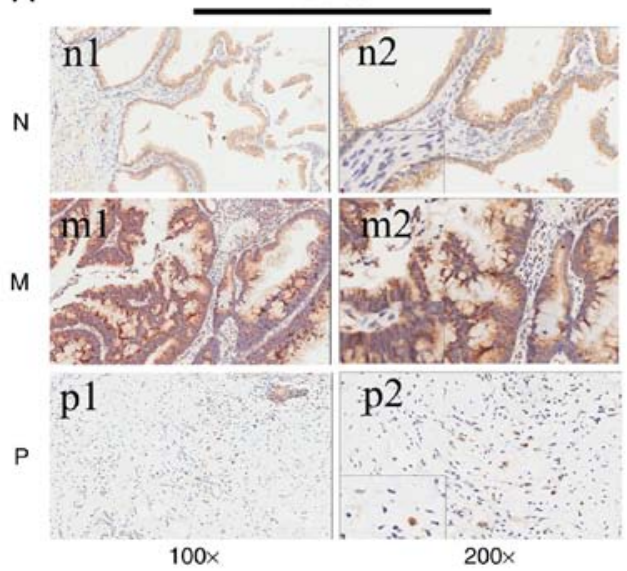

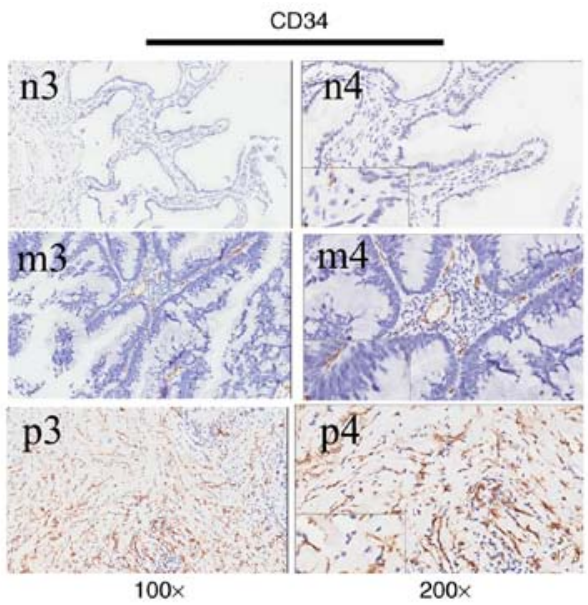

$100 x$
$200 x$
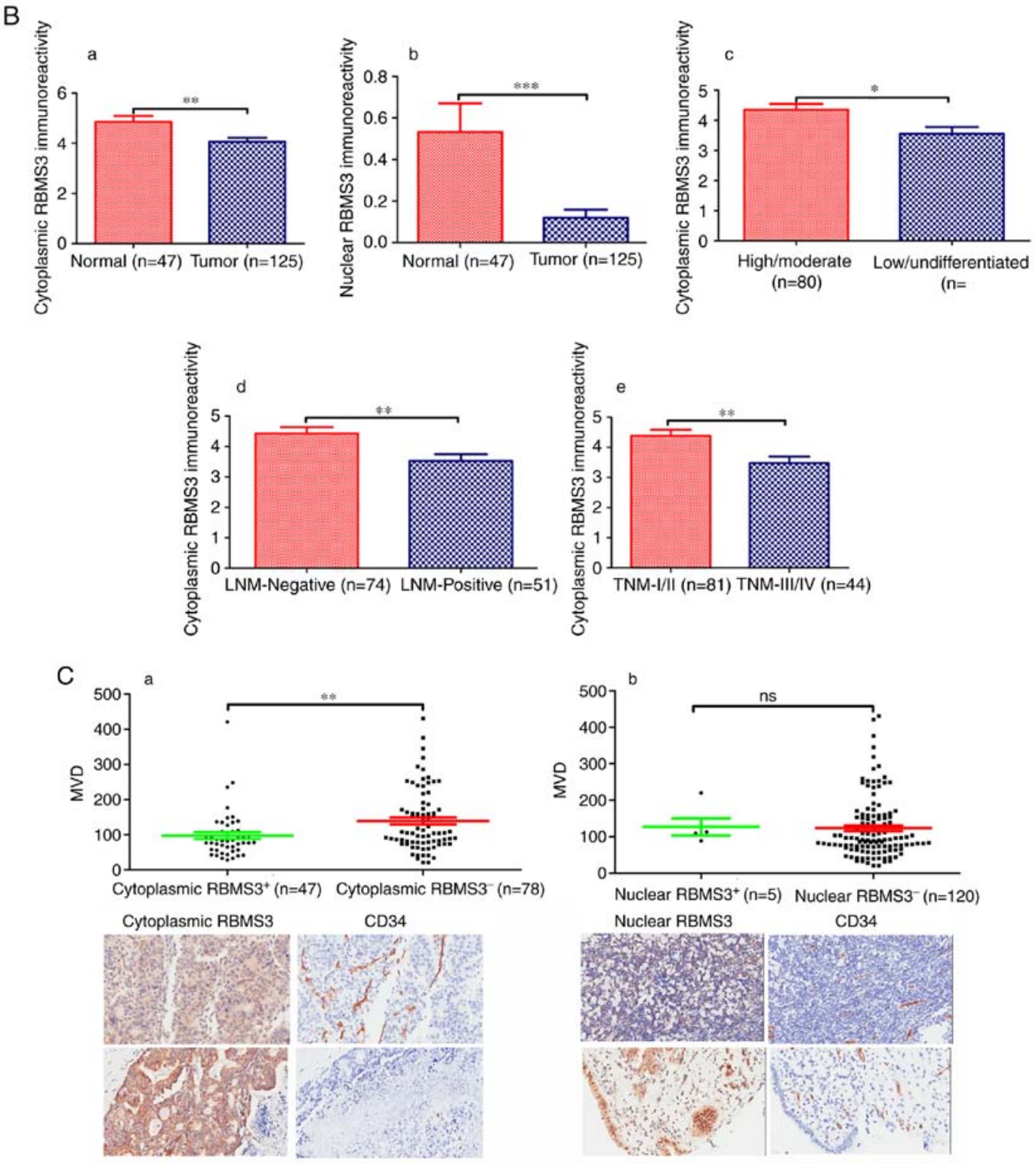

Figure 2. Immunohistochemical staining of RBMS3 and CD34 protein in GBC and random normal gallbladder tissues. (A) Representative images of RBMS3 and CD34 as follows: Normal gallbladder tissues (N) with cytoplasmic RBMS3 ${ }^{+}$expression (n1 and n2) and low MVD (n3 and n4) expression; middle differentiated (M) GBC with cytoplasmic RBMS3 ${ }^{+}$expression ( $\mathrm{m} 1$ and $\mathrm{m} 2$ ) and low MVD (m3 and m4) expression; poorly differentiated (P) GBC with cytoplasmic RBMS3- expression (p1 and p2) and high MVD (p3 and p4) expression. Magnification: x100 (n1, n3, m1, m3, p1 and p3) and x400 insertion x200 (n2, n4, m2, $\mathrm{m} 4, \mathrm{p} 2$ and p4). (B) Immunoreactivity scores of cytoplasmic RBMS3 and nuclear RBMS3 staining in (a and b) normal gallbladder tissues and tumor tissues, (c) high/moderate and low/undifferentiated, (d) LNM-negative and LNM-positive, and (e) TNM-I/II and TNM-III/IV are represented as the mean \pm SEM. (C) MVD counts of tumor tissues. (a) MVD counting in tumor tissues with cytoplasmic RBMS3 ${ }^{+}$and cytoplasmic RBMS3 ${ }^{-}$expression; (b) MVD counting in tumor tissues with nuclear RBMS3 ${ }^{+}$and nuclear RBMS3 ${ }^{-}$expression. ${ }^{*} \mathrm{P}<0.05,{ }^{* *} \mathrm{P}<0.01,{ }^{* * *} \mathrm{P}<0.001$ vs. NC. ns, not significant; RBMS3, RNA binding motif, single-stranded interacting protein 3; GBC, gallbladder carcinoma; MVD, microvessel density; LNM, lymph node metastasis. 
Table III. Association between cytoplasmic RBMS3 expression and clinicopathological variables $(\mathrm{n}=125)$.

\begin{tabular}{|c|c|c|c|c|}
\hline \multirow{2}{*}{$\begin{array}{l}\text { Clinicopathological } \\
\text { variables }\end{array}$} & \multirow[b]{2}{*}{ Total } & \multicolumn{2}{|c|}{ Cytoplasmic RBMS3 expression } & \multirow[b]{2}{*}{ P-value } \\
\hline & & Positive & Negative & \\
\hline Sex & & & & 0.182 \\
\hline Male & 34 & $16(47.1)$ & $18(52.9)$ & \\
\hline Female & 91 & $31(34.1)$ & $60(65.9)$ & \\
\hline Age (years) & & & & 0.417 \\
\hline$<68$ & 58 & 24 (41.4) & 34 (58.6) & \\
\hline$\geq 68$ & 67 & $23(34.3)$ & $44(65.7)$ & \\
\hline Tumor size $(\mathrm{cm})$ & & & & 0.344 \\
\hline$<2$ & 60 & $20(33.3)$ & 40 (66.7) & \\
\hline$\geq 2$ & 65 & $27(41.5)$ & $38(58.5)$ & \\
\hline Differentiation & & & & 0.023 \\
\hline High/moderate & 80 & $36(45)$ & $44(55)$ & \\
\hline Low/undifferentiated & 45 & $11(24.4)$ & $34(75.6)$ & \\
\hline Depth of invasion & & & & 0.972 \\
\hline $\mathrm{T} 1 / \mathrm{T} 2$ & 37 & $14(37.8)$ & $23(62.2)$ & \\
\hline $\mathrm{T} 3 / \mathrm{T} 4$ & 88 & $33(37.5)$ & $55(62.5)$ & \\
\hline Lymph node metastasis & & & & 0.007 \\
\hline Yes & 51 & $12(23.5)$ & 39 (76.5) & \\
\hline No & 74 & $35(47.3)$ & $39(52.7)$ & \\
\hline TNM & & & & 0.004 \\
\hline $\mathrm{I} / \mathrm{II}$ & 81 & $38(46.9)$ & $43(53.1)$ & \\
\hline III/IV & 44 & $9(20.5)$ & $35(79.5)$ & \\
\hline Gallstones & & & & 0.757 \\
\hline Yes & 83 & $32(38.6)$ & $51(61.4)$ & \\
\hline No & 42 & $15(35.7)$ & $27(64.3)$ & \\
\hline $\mathrm{AFP}(\mu \mathrm{g} / \mathrm{l})$ & & & & 0.193 \\
\hline$<20$ & 120 & $47(39.2)$ & $73(60.8)$ & \\
\hline$\geq 20$ & 5 & $0(0)$ & $5(100)$ & \\
\hline CEA (ng/ml) & & & & 0.419 \\
\hline$<5$ & 99 & $39(39.4)$ & $60(60.6)$ & \\
\hline$\geq 5$ & 26 & $8(30.8)$ & $18(69.2)$ & \\
\hline CA199 (U/ml) & & & & 0.342 \\
\hline$<37$ & 81 & $28(34.6)$ & $53(65.4)$ & \\
\hline$\geq 37$ & 44 & $19(43.2)$ & $25(56.8)$ & \\
\hline
\end{tabular}

$\mathrm{P}<0.05$ was defined as statistically significant and is indicated in bold. RNA binding motif, single-stranded interacting protein 3; TNM, tumor-node-metastasis; AFP, alpha fetoprotein; CEA, carcino-embryonic antigen; CA199, carbohydrate antigen 199.

was significantly decreased when compared to matched controls $(0.043 \pm 0.051, \mathrm{P}=0.0009$; Fig. 1A). The differences with $<1$-fold change were defined as downregulation ( $\mathrm{GBC} /$ normal $<1$ ) and those with $>1$-fold change as upregulation (GBC/normal >1) in RBMS3 mRNA expression in GBC tissues compared with normal tissues. The results revealed that $78.05 \%(32 / 41)$ of GBC tissues expressed a lower level of RBMS3 compared with the matched normal tissues (Fig. 1B). In addition, to further investigate whether protein expression was consistent with the results of qPCR, RBMS3 protein levels in the matched tumor and normal specimens were determined by western blotting and are presented in Fig. 1C. Compared with that in adjacent normal controls, the expression of RBMS3 protein was decreased in the GBC specimens. Collectively, these results indicated that in this Chinese GBC cohort, RBMS3 expression was decreased at both the mRNA and protein levels.

Immunostaining for RBMS3. To elucidate the biological significance of RBMS3 in GBC, RBMS3 protein expression was analyzed in a tissue microarray (TMA) of 125 clinical GBC tissue samples and 47 normal controls using IHC. In 
Table IV. Association between nuclear RBMS3 expression and clinicopathological variables $(\mathrm{n}=125)$.

\begin{tabular}{|c|c|c|c|c|}
\hline \multirow{2}{*}{$\begin{array}{l}\text { Clinicopathological } \\
\text { variables }\end{array}$} & \multirow[b]{2}{*}{ Total } & \multicolumn{2}{|c|}{ Nuclear RBMS3 expression } & \multirow[b]{2}{*}{ P-value } \\
\hline & & Positive & Negative & \\
\hline Sex & & & & 0.999 \\
\hline Male & 34 & $1(2.9)$ & $33(97.1)$ & \\
\hline Female & 91 & $4(4.4)$ & 87 (95.6) & \\
\hline Age (years) & & & & 0.869 \\
\hline$<68$ & 58 & $3(5.2)$ & $55(94.8)$ & \\
\hline$\geq 68$ & 67 & $2(3)$ & $65(97)$ & \\
\hline Tumor size (cm) & & & & 0.927 \\
\hline$<2$ & 60 & $3(5)$ & $57(95)$ & \\
\hline$\geq 2$ & 65 & $2(3.1)$ & $63(93.3)$ & \\
\hline Differentiation & & & & 0.506 \\
\hline High/moderate & 80 & $2(2.5)$ & $78(97.5)$ & \\
\hline Low/undifferentiated & 45 & $3(6.7)$ & $42(93.3)$ & \\
\hline Depth of invasion & & & & 0.327 \\
\hline $\mathrm{T} 1 / \mathrm{T} 2$ & 37 & $0(0)$ & $37(100)$ & \\
\hline $\mathrm{T} 3 / \mathrm{T} 4$ & 88 & $5(5.7)$ & $83(94.3)$ & \\
\hline Lymph node metastasis & & & & 0.669 \\
\hline Yes & 51 & $3(5.9)$ & $48(94.1)$ & \\
\hline No & 74 & $2(2.7)$ & $72(97.3)$ & \\
\hline TNM & & & & 0.479 \\
\hline $\mathrm{I} / \mathrm{II}$ & 81 & $2(2.5)$ & 79 (97.5) & \\
\hline III/IV & 44 & $3(6.8)$ & $41(92.2)$ & \\
\hline Gallstones & & & & 0.999 \\
\hline Yes & 83 & $3(3.6)$ & $80(96.4)$ & \\
\hline No & 42 & $2(4.8)$ & $40(95.2)$ & \\
\hline $\operatorname{AFP}(\mu \mathrm{g} / \mathrm{l})$ & & & & 0.999 \\
\hline$<20$ & 120 & $5(4.2)$ & $115(95.8)$ & \\
\hline$\geq 20$ & 5 & $0(0)$ & $5(100)$ & \\
\hline CEA (ng/ml) & & & & 0.999 \\
\hline$<5$ & 99 & $4(4)$ & $95(96)$ & \\
\hline$\geq 5$ & 26 & $1(3.8)$ & $25(96.2)$ & \\
\hline CA199 (U/ml) & & & & 0.999 \\
\hline$<37$ & 81 & $3(3.7)$ & $78(96.3)$ & \\
\hline$\geq 37$ & 44 & $2(4.5)$ & $42(95.5)$ & \\
\hline
\end{tabular}

RNA binding motif, single-stranded interacting protein 3; TNM, tumor-node-metastasis; AFP, alpha fetoprotein; CEA, carcino-embryonic antigen; CA199, carbohydrate antigen 199.

agreement with previous studies, the positive immunohistochemical staining was predominantly located in the cytoplasm and/or nucleus $(12,13)$. The expression levels of RBMS3 in the cytoplasm and nucleus are summarized in Table II. The results revealed that nuclear RBMS3 and cytoplasmic RBMS3 expression in GBC were significantly lower than those in the normal controls $(\mathrm{P}=0.004$ and $\mathrm{P}=0.005$, respectively; data not shown). Representative images of RBMS3 immunohistochemical staining in GBC tissue and normal controls are shown in Fig. 2A. In summary, the present results revealed that RBMS3 was downregulated in GBC.
Associations of RBMS3 expression with GBC clinicopathological parameters. To further characterize the roles of RBMS3 in GBC carcinogenesis, the associations between RBMS3 expression in GBC tissues and clinicopathological parameters of GBC patients were analyzed. The tumor TNM stage was classified as 'early' (I/II) or 'advanced' (III/IV). The lymph node stages were divided into lymph node-negative (No) or lymph node-positive (Yes). As revealed in Tables III and IV, the expression of cytoplasmic RBMS3 in GBC was significantly associated with histopathological differentiation (high/moderate vs. low/undifferentiated, $\mathrm{P}=0.023$ ), lymph node 
Table V. Univariate and multivariate analysis of the correlation between clinicopathological parameters and prognostic significance of GBC patients.

\begin{tabular}{|c|c|c|c|c|}
\hline \multirow[b]{2}{*}{ Variables } & \multicolumn{2}{|c|}{ Univariate analysis } & \multicolumn{2}{|c|}{ Multivariate analysis } \\
\hline & $\mathrm{HR}(95 \% \mathrm{CI})$ & P-value & $\mathrm{HR}(95 \% \mathrm{CI})$ & P-value \\
\hline Sex (male vs. female) & $1.188(0.775-1.822)$ & 0.43 & & NA \\
\hline Age (years) (<68 vs. $\geq 68)$ & $1.325(0.912-1.924)$ & 0.14 & & NA \\
\hline Tumor diameter (cm) (<2 vs. $\geq 2)$ & $1.847(1.263-2.700)$ & 0.002 & $1.526(0.963-2.418)$ & 0.072 \\
\hline $\begin{array}{l}\text { Differentiation (low/undifferentiated vs. } \\
\text { high/moderate) }\end{array}$ & $0.314(0.211-0.468)$ & 1.14E-08 & $0.564(0.343-0.925)$ & 0.023 \\
\hline Depth of invasion (T1/TI vs. T3/T4) & $2.277(1.460-3.550)$ & 2.85E-04 & $1.898(1.157-3.114)$ & 0.011 \\
\hline Lymph node metastasis (no vs. yes) & $1.880(1.282-2.757)$ & 0.001 & $1.063(0.467-2.420)$ & 0.884 \\
\hline TNM stages (I/II vs. III/IV) & $2.215(1.486-3.301)$ & 9.38E-05 & $1.346(0.568-3.190)$ & 0.5 \\
\hline Gallstones & $0.961(0.653-1.415)$ & 0.842 & & NA \\
\hline $\operatorname{AFP}(<20$ vs. $\geq 20)$ & $1.927(1.220-3.042)$ & 0.005 & $1.855(1.091-3.155)$ & $\mathbf{0 . 0 2 3}$ \\
\hline CEA $(<5$ vs. $\geq 5)$ & $1.718(0.693-4.260)$ & 0.243 & & NA \\
\hline CA199 (<37 vs. $\geq 37$ ) & 1.609 (1.094-2.367) & 0.016 & $1.310(0.868-1.977)$ & 0.198 \\
\hline $\begin{array}{l}\text { Nuclear RBMS3 expression } \\
\text { (positive vs. negative) }\end{array}$ & $1.224(0.495-3.025)$ & 0.662 & & NA \\
\hline $\begin{array}{l}\text { Cytoplasmic RBMS3 expression } \\
\text { (positive vs. negative) }\end{array}$ & $0.508(0.339-0.762)$ & 0.001 & $0.450(0.294-0.688)$ & 2.29E-04 \\
\hline
\end{tabular}

Variables with P-values $>0.05$ in the univariate models were not adapted (NA) in the multivariate analysis. P $<0.05$ was defined as statistically significant and is indicated in bold. GBC, gallbladder carcinoma; CI, confidence interval; HR, hazard ratio; TNM, tumor-node-metastasis; AFP, alpha fetoprotein; CEA, carcino-embryonic antigen; CA199, carbohydrate antigen 199; RNA binding motif, single-stranded interacting protein 3 .

metastasis (Yes vs. No, $\mathrm{P}=0.007$ ) and TNM tumor stage (I/II vs. III/IV, P=0.004), while the expression of nuclear RBMS3 was not associated to any clinical parameters. Compared to that in low/undifferentiated, lymph node-positive and TNM 'advanced (III/IV)' stage, the immunoreactivity of cytoplasmic RBMS3 was markedly increased in high/moderate histopathological differentiation, lymph node-negative, TNM 'early (I/II)' stage and normal controls. Immunoreactivity of cytoplasmic and nuclear RBMS3 in GBC tissues and normal controls and associations with histopathological differentiation (high/moderate vs. low/undifferentiated), lymph node metastasis (Yes vs. No) and TNM tumor stage (I/II vs. III/IV) are presented in Fig. 2Ba-e. Collectively, the present findings revealed that cytoplasmic RBMS3 expression was associated with histopathological differentiation, lymph node metastasis and TNM tumor stage.

Correlation between angiogenesis and RBMS3 expression. Previous studies revealed that RBMS3 could regulate angiogenesis in NPC and GC $(12,15)$. However, the role of RBMS3 has not been reported in GBC. Therefore, the correlation between MVD and RBMS3 expression in our TMA was analyzed. MVD was quantified by counting CD34-positive endothelial cells.

The MVD counts in the cytoplasm of the RBMS3-negative group (cytoplasmic RBMS3-, 139.20ะ9.953) were significantly higher than those in the cytoplasmic RBMS3-positive group (cytoplasmic $\mathrm{RBMS}^{+}$, 97.81 $\pm 9.860, \mathrm{P}=0.0065$ ) as revealed in Fig. 2Ca, while MVD was not related to the expression of nuclear RBMS3, as revealed in Fig. 2Cb. In conclusion, the present results indicated that cytoplasmic RBMS3 was associated with GBC angiogenesis.

Survival analysis. Based on the aforementioned results, it was determined that RBMS3 expression was associated with GBC progression. Thus, the prognostic value of RBMS3 expression in patients with GBC was evaluated using Kaplan-Meier analysis and log-rank test. Kaplan-Meier survival curves revealed that cytoplasmic RBMS3-negative expression (cytoplasmic RBMS3 $^{-}$) was associated with worse overall survival (OS; log-rank test: $\mathrm{P}<0.001$; Fig. $3 \mathrm{~A}$ ), while overall survival was not related to the expression of nuclear RBMS3, as revealed in Fig. 3B. Patients with cytoplasmic RBMS3- expression exhibited shorter OS (mean 12.29 \pm 0.636 months) than those with cytoplasmic RBMS3 ${ }^{+}$tumors (mean 16.81 1.929 months, $\mathrm{P}<0.001)$, with an adjusted HR of 0.450 (95\% CI: 0.294-0.688, $\mathrm{P}<0.001)$. Collectively, the present results indicated that cytoplasmic RBMS3 was significantly associated with the clinical prognosis of GBC and may become a prognostic biomarker for GBC.

Univariate and multivariate Cox regression analyses. The predictive roles of RBMS3 in GBC prognosis were further assessed by Cox regression analysis. The univariate Cox regression analysis revealed significant correlations between OS and tumor size, differentiation, depth of invasion, lymph node 

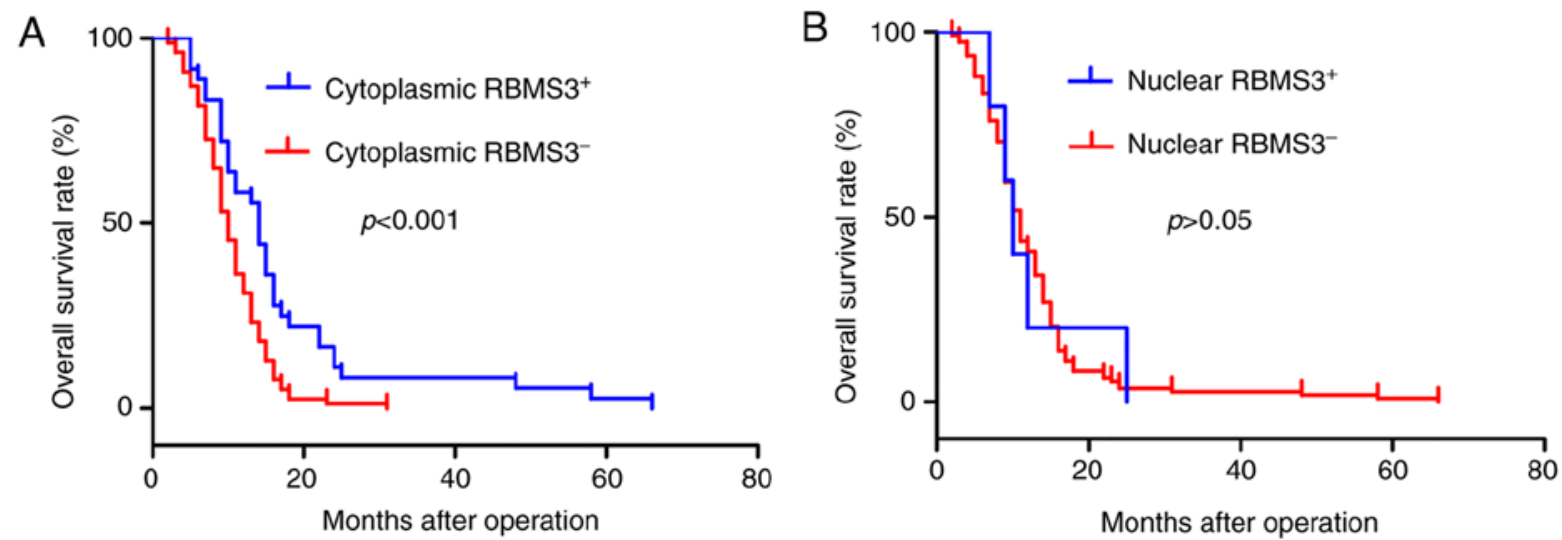

Figure 3. Kaplan-Meier survival analysis with log-rank test for the OS of 125 GBC. (A) The OS of patients with cytoplasmic RBMS3-and cytoplasmic $\mathrm{RBMS3}^{+}$. (B) The OS of patients with nuclear RBMS3+ and nuclear RBMS3- expression. OS, overall survival; GBC, gallbladder carcinoma; RBMS3, RNA binding motif, single-stranded interacting protein 3.

metastasis, TNM stages, AFP, CA199 levels and cytoplasmic RBMS3 expression (Table V). Furthermore, a multivariate Cox regression analysis was performed for these factors. As a result, differentiation, depth of invasion, AFP and cytoplasmic RBMS3 expression were identified as independent prognostic factors (Table V). Collectively, the present results identified cytoplasmic RBMS3 expression as an independent prognostic factor for GBC.

RBMS3 overexpression inhibits the growth of GBC cells in vitro. Given the significant downregulation of RBMS3 in GBC and the association between the downregulation of cytoplasmic RBMS3 expression and poor clinical prognosis, it was postulated that RBMS3 may inhibit GBC cell growth. To investigate whether RBMS3 has tumor suppressive ability, we stably overexpressed RBMS3 (OE) in GBC-SD and SGC996 GBC cell lines by lentivirus infection, which was confirmed by western blotting, while the empty vector lentivirus (NC) served as a control.

Then, a cell proliferation and colony formation assays were performed to evaluate the effects of RBMS3 on the growth of GBC-SD and SGC996 cells. As revealed in Fig. 4A, it was determined that overexpression of RBMS3 significantly inhibited the proliferation ability of GBC-SD and SGC996 cells compared with the control. Furthermore, colony formation assays similarly revealed that overexpression of RBMS3 markedly decreased the number and size of the colonies compared with the control (Fig. 4B). These results indicated an inhibitory role for RBMS3 in the proliferation of GBC cells in vitro, supporting the hypothesis that RBMS3 may act as a tumor suppressor in GBC.

RBMS3 overexpression promotes the apoptosis of GBC cells in vitro. Previous findings strongly suggest that RBMS3 is a prominent apoptosis inducer in $\operatorname{GBC}(13,15)$. To further verify our hypothesis, the apoptosis levels between the two groups (OE vs. NC) in both cell lines (GBC-SD and SGC996) were examined using flow cytometry and it was revealed that RBMS3 promoted apoptosis in both cell lines (Fig. 5A and B). These results support the tumor suppressor role of RBMS3 in GBC via induction of tumor cell apoptosis.

\section{Discussion}

Multiple regions within the short arm of chromosome 3 (3p) are frequently deleted in numerous human solid tumors including GBC, representing a genetic alteration hotspot. The 3p24 gene RBMS3 has been identified as a candidate TSG in LSCC, NPC, ESCC, and GC $(11,12,14,15)$. Previous studies revealed that in LSCC, NPC and ESCC, RBMS3 was mainly found in the nucleus, and its low nuclear expression predicted poor prognosis $(11,14,15)$, while in GC, RBMS3 was mainly found in the cytoplasm and its low expression in the cytoplasm predicted poor prognosis (12). In the present study, it was revealed that RBMS3 is a candidate tumor biomarker for GBC (Fig. 6). It was demonstrated that in GBC tissue, both the mRNA and protein expression levels of RBMS3 were significantly downregulated. RBMS3 protein staining was detected in the nucleus and/or cytoplasm of GBC cells, and both nuclear and cytoplasmic RBMS3 staining was significantly reduced in GBC tissues compared with normal controls, suggesting a pivotal role for RBMS3 in GBC development and progression.

Subsequent studies have revealed that RBMS3 is downregulated in a number of solid tumors and plays an important role in tumor progression and angiogenesis. For instance, Li et al (11) revealed that ESCC patients with RBMS3 downregulation had worse clinical outcomes, and RBMS3 expression effectively suppressed cell growth, colony formation, and tumor formation in nude mice through c-Myc downregulation. Wu et al (12) revealed that RBMS3 may modulate the cellular localization of the transcription factor HIF1A and thus regulate tumor angiogenesis, and GC patients with low RBMS3 expression had worse clinical outcomes. Another study revealed that downregulation of RBMS3 was detected in NPC cell lines and primary NPC tissues and overexpression of RBMS3 in the NPC cell lines markedly induced cell apoptosis and inhibited microvessel formation by targeting caspase-9, PARP, MMP2 and $\beta$-catenin (15). RBMS3 was also suggested to play a role in cell cycle arrest at the G1/S checkpoint by upregulating p53 and p21 and downregulating cyclin E and CDK2 expression (15). Recently, Yang et al revealed that RBMS3 overexpression markedly suppressed proliferation, migration, and invasion by inhibiting the protein expression of $\beta$-catenin, cyclin D1, 

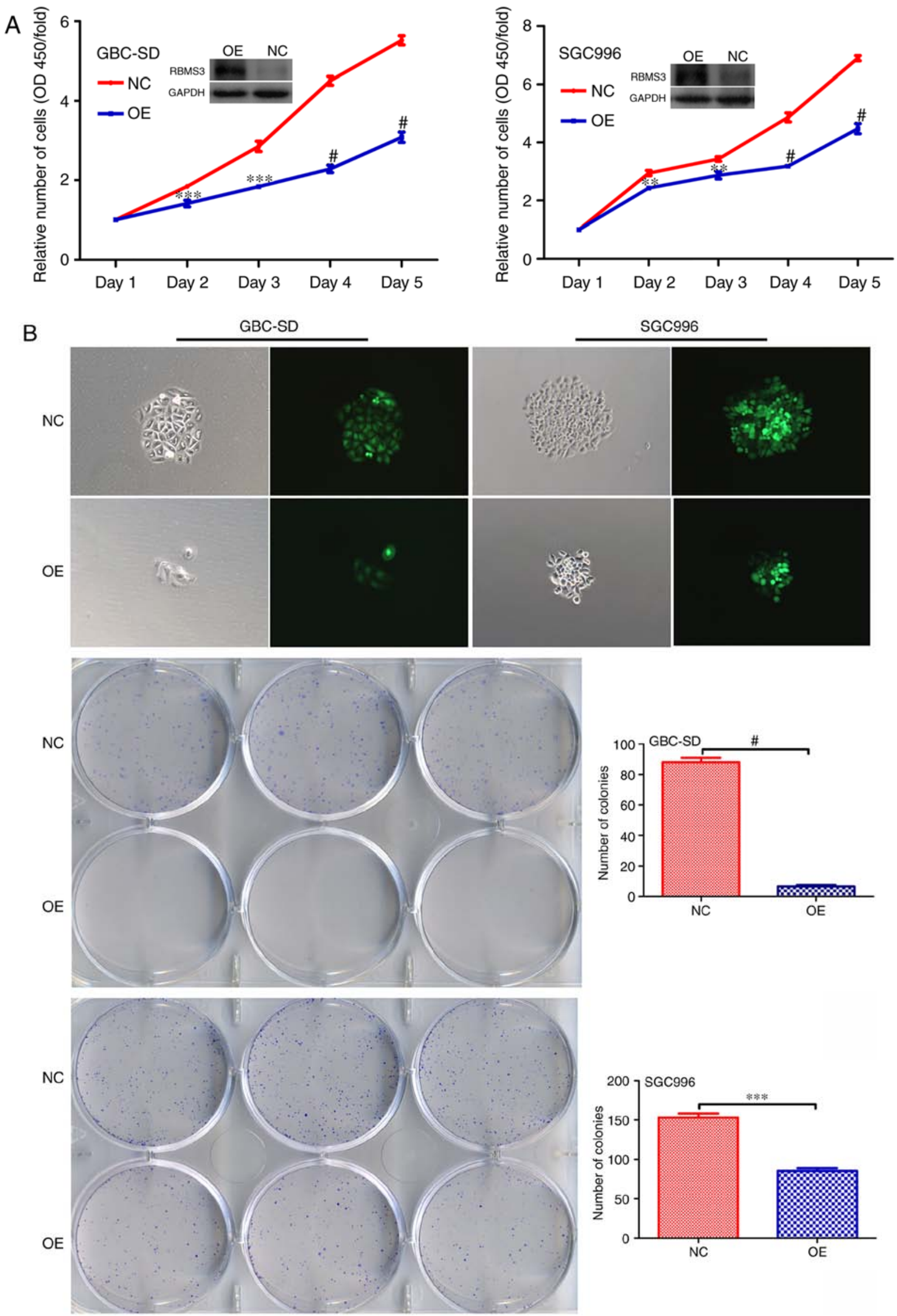

Figure 4. RBMS3 controls GBC cell growth in vitro. GBC-SD and SGC996 cells were infected with lentiviruses carrying RBMS3 overexpression vector (OE) or negative control vector (NC) and then were subjected to (A) CCK-8 assay and (B) colony formation assay. RBMS3 overexpression inhibited GBC cell proliferation. Each experiment was repeated three times. Values are expressed as the means $\pm \mathrm{SD} .{ }^{* * *} \mathrm{P}<0.01,{ }^{* * * *} \mathrm{P}<0.001,{ }^{*} \mathrm{P}<0.0001$. RBMS3, RNA binding motif, single-stranded interacting protein 3; GBC, gallbladder carcinoma. 


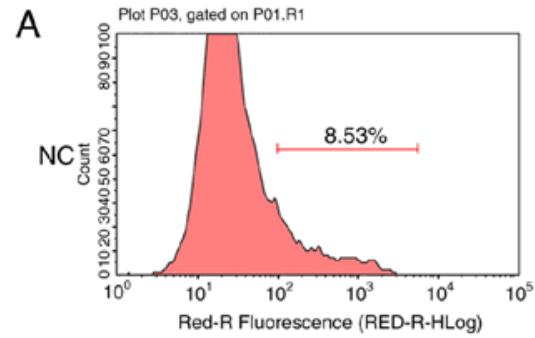

ANNEXIN-V

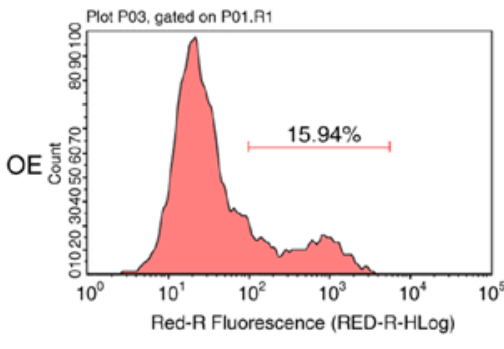

ANNEXIN-V

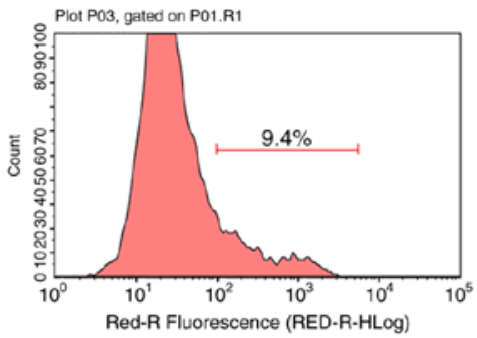

ANNEXIN-V

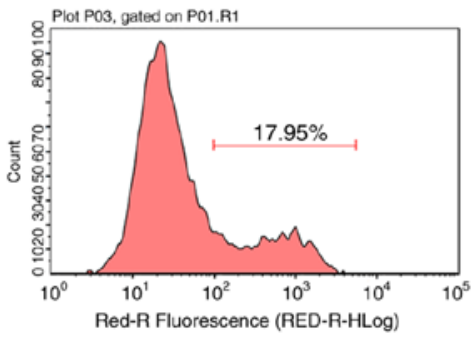

ANNEXIN-V
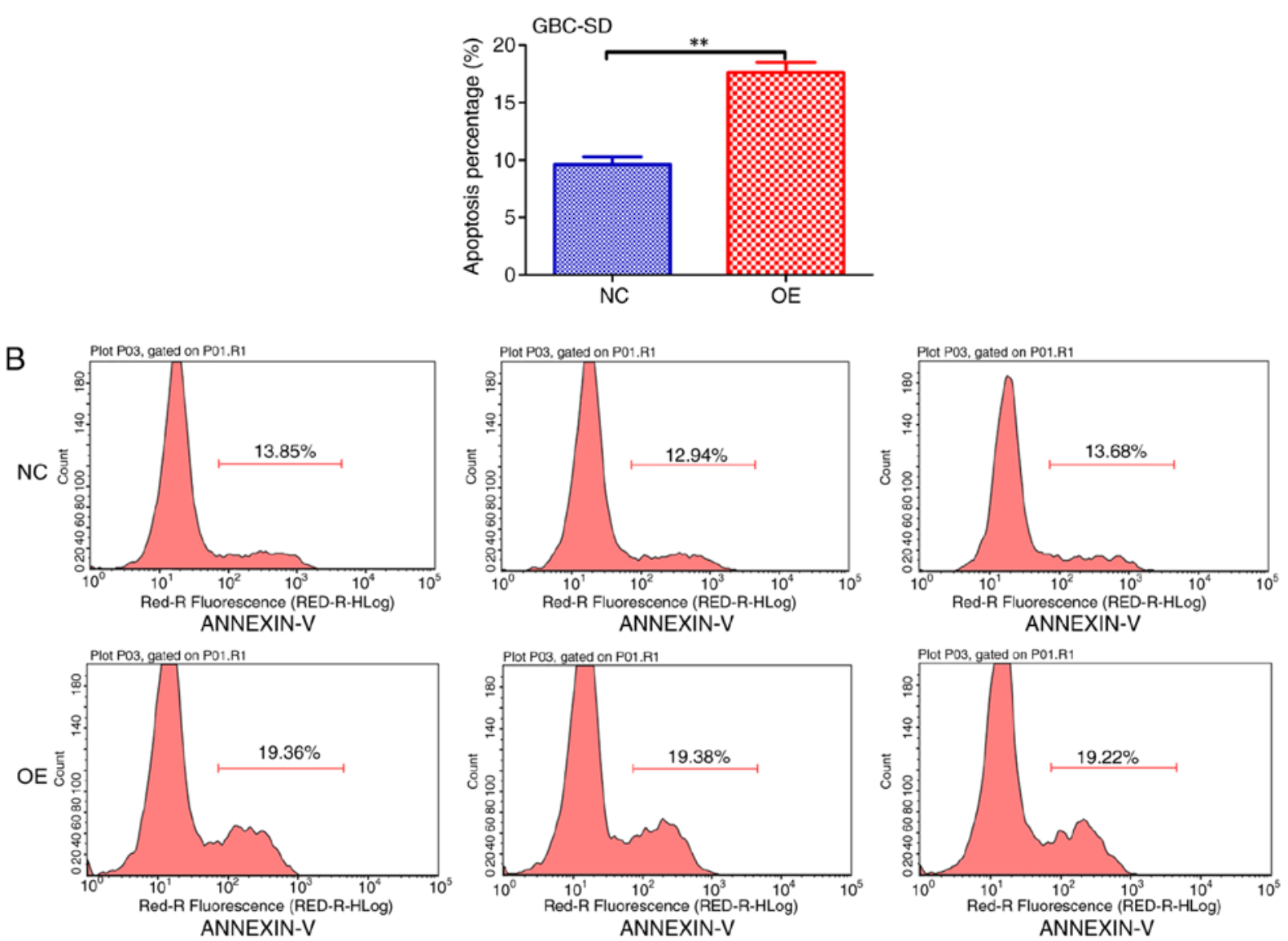

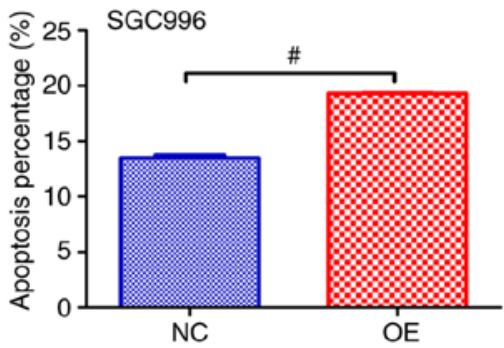

Figure 5. Ectopic expression of RBMS3 induces GBC cell apoptosis. GBC-SD and SGC996 cells were infected with lentiviruses carrying RBMS3 overexpression vector (OE) or negative control vector (NC). Flow cytometry with APC-conjugated Annexin V staining determined changes in apoptosis in (A) GBC-SD cells and (B) SGC996 cells in the presence of RBMS3 overexpression or the negative control. Values are expressed as the means $\pm \mathrm{SD}$. ${ }^{* *} \mathrm{P}<0.01,{ }^{*} \mathrm{P}<0.0001$. RBMS3, RNA binding motif, single-stranded interacting protein 3; GBC, gallbladder carcinoma. 


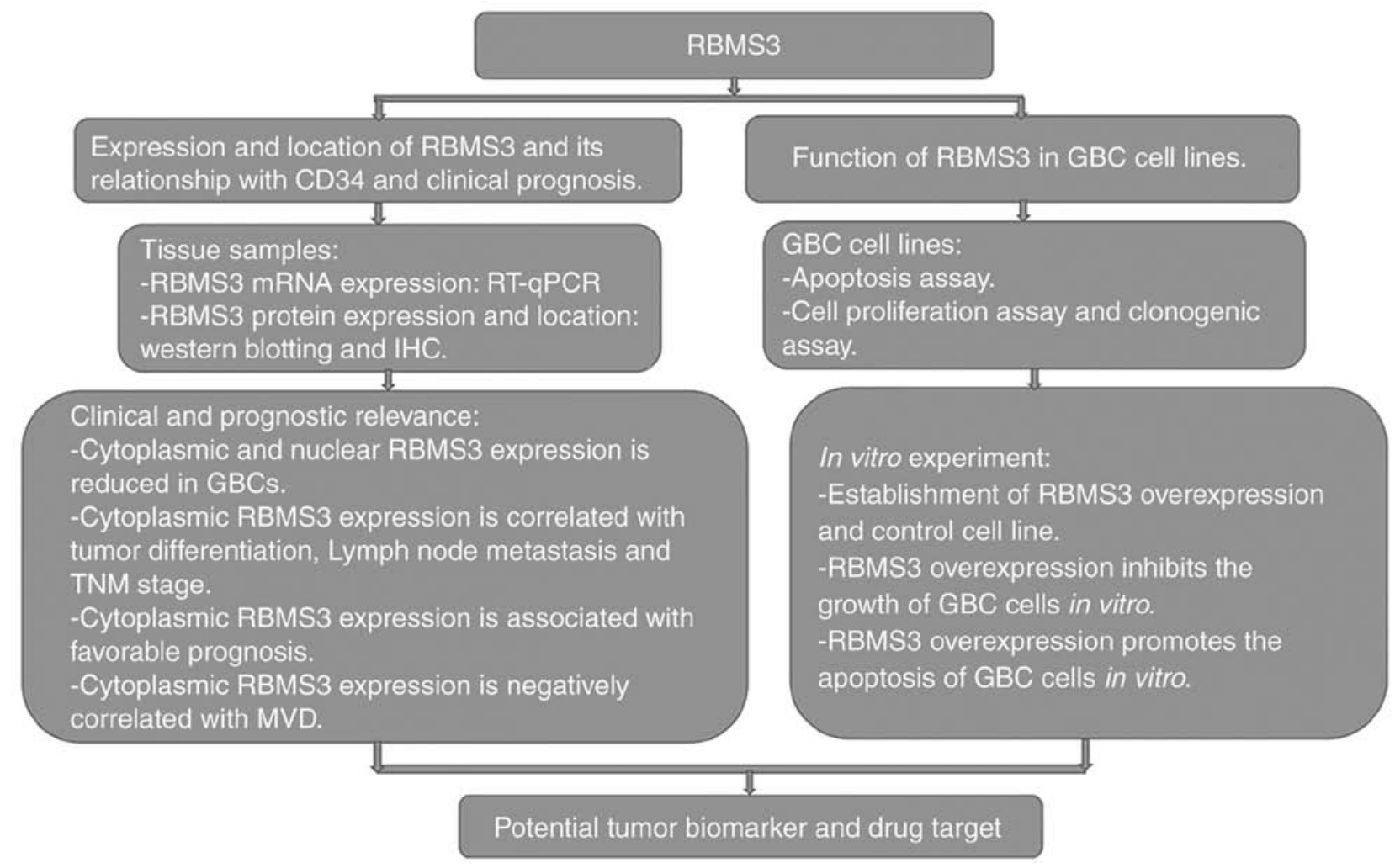

Figure 6. A summary diagram of the role of RBMS3 in GBC. RBMS3, RNA binding motif, single-stranded interacting protein 3; GBC, gallbladder carcinoma.

and c-Myc in breast cancer cells (13). Consistent with the aforementioned studies, in the present study, it was observed that cytoplasmic RBMS3- GBC patients had significantly worse prognosis and higher tumor angiogenesis compared with cytoplasmic RBMS3 ${ }^{+}$GBC patients. However, no association of nuclear RBMS3 with GBC prognosis or angiogenesis was revealed. This result is consistent with a previous study showing RBMS3 accumulation in the cytoplasm and strongly suggesting a cytoplasmic function for RBMS3 (8). Therefore, cytoplasmic RBMS3 expression may play more important roles in GBC than nuclear RBMS3 expression. Moreover, multivariate Cox analysis further confirmed cytoplasmic RBMS3 as an independent prognostic factor for GBC, and RBMS3 overexpression markedly suppressed the proliferation and clonogenicity of GBC cells and promoted apoptosis in vitro. This result is consistent with previous studies on RBMS3 as an MSSP family protein to regulate cell proliferation and apoptosis, both of which are crucial biological processes in tumorigenesis. However, it was revealed that RBMS3 is mainly located in the cytoplasm rather than the nucleus in GBC. It is surmised that it can play a biological function in GBC by regulating target-gene expression post-transcriptionally through RNA binding. Previous research revealed that RBMS3 can increase the half-life of Prx 1 mRNA, thus increasing the expression of Prx1 protein, while Prx1 can interact with p66Shc, leading to changes in mitochondrial membrane permeability cytochrome $c$ release and apoptosis (15). However, whether RBMS3 can induce apoptosis through a similar pathway in GBC requires further investigation. Collectively, these data indicated that cytoplasmic RBMS3 is a novel TSG in GBC, and its downregulation facilitates the development and progression of GBC.
Tumor angiogenesis is correlated with invasion, metastasis, treatment resistance and poor prognosis in some cancers including GBC (26-29). A number of tumor therapeutic strategies are being developed to inhibit tumor angiogenesis $(30,31)$. As previously reported, RBMS3 may regulate tumor angiogenesis by modulating the location of HIF1A (12) and RBMS3 may inhibit microvessel formation in NPC cell lines through downregulation of MMP2 and $\beta$-catenin and inactivation of its downstream targets cyclin-D1, c-Myc, MMP7, and MMP9 (15). There have been no studies on the association between MVD and RBMS3 expression in GBC. In the present study, a strong association between cytoplasmic RBMS3 expression and MVD was observed. GBC tissues with low expression of cytoplasmic RBMS3 had high MVD counts compared with high expression of cytoplasmic RBMS3, while nuclear RBMS3 expression was not related to MVD counts. Therefore, cytoplasmic RBMS3 may contribute to angiogenesis in GBC. Moreover, it was also revealed that GBC tissues at the advanced stage with positive nodal metastasis and in poor histological differentiation degree, had lower cytoplasmic RBMS3 expression, indicating that cytoplasmic RBMS3 plays a significant role in tumor invasion and metastasis. According to the characteristics of GBC progression, patients with advanced tumor stage, lymph node metastasis and poor histological differentiation degree may be closely correlated with worse clinical outcome. Thus, these results also indicated that cytoplasmic RBMS3 may play an important tumor-suppressive role in GBC progression.

In conclusion, the present results indicated that, as a member of the MSSPS family, RBMS3 could be an independent prognostic factor for $\mathrm{GBC}$ and the low expression of cytoplasmic RBMS3 in GBC patients was significantly 
correlated with advanced tumor stage, lymph node metastasis, poor histological differentiation degree, high tumor angiogenesis and poor prognosis, suggesting that it may be a useful molecular marker in GBC. However, there were some limitations in this study. First, in the present study, the number of cases was relatively small, and a larger number of patients would help to better understand the clinical diagnostic and prognostic value of RBMS3 dysregulation in GBC progression. In-depth investigation of the tumor-suppressive roles and molecular mechanisms of RBMS3 in GBC will not only greatly improve our biological understanding of GBC but also suggest novel approaches for the clinical treatment of GBC.

\section{Acknowledgments}

We thank Mr. Shangxin Zhang for the technical support. We thank Mrs. Mei Li for the helpful suggestions on this manuscript. We thank Dr Yuanyuan Chen for supporting in the manuscript preparation. We further thank all volunteers who participated in this study.

\section{Funding}

The present study was supported by a grant from the Provincial Natural Science Foundation of Anhui (no. 1808085MH238) and the National Natural Science Foundation of China (no. 81874063).

\section{Availability of data and materials}

The datasets used and/or analyzed during the current study are available from the corresponding author upon reasonable request.

\section{Authors' contributions}

YW and DM performed the experiments and wrote the manuscript. YY collected and analyzed the data. RS and QY constructed the tissue microarray. JB and YS assisted with the experiments and compiled the clinical data. DY assisted with the statistical analysis. YL and DS conceived, designed, supervised and wrote the manuscript. All authors read and approved the final manuscript and agree to be responsible for all aspects of the work in ensuring that the accuracy or integrity of any part of the work are appropriately investigated and resolved.

\section{Ethics approval and consent to participate}

The present study was approved by the Institute Research Ethics Committee of the Armed Police Corps Hospital of Anhui and written informed consent was obtained from all patients involved.

\section{Patient consent for publication}

Not applicable.

\section{Competing interests}

The authors declare that they have no competing interests.

\section{References}

1. Siegel RL, Miller KD and Jemal A: Cancer statistics, 2015. CA Cancer J Clin 65: 5-29, 2015.

2. Hundal R and Shaffer EA: Gallbladder cancer: Epidemiology and outcome. Clin Epidemiol 6: 99-109, 2014.

3. Cai Y and Sablina AA: Cancer-associated chromosomal deletions: Size makes a difference. Cell Cycle 15: 2850-2851, 2016.

4. Pezzolo A, Sementa AR, Lerone M, Morini M, Ognibene M, Defferrari R, Mazzocco K, Conte M, Gigliotti AR, Garaventa A, et al: Constitutional 3p26.3 terminal microdeletion in an adolescent with neuroblastoma. Cancer Biol Ther 18: 285-289, 2017.

5. Togo Y, Yoshikawa Y, Suzuki T, Nakano Y, Kanematsu A, Zozumi M, Nojima $M$, Hirota $S$, Yamamoto $S$ and Hashimoto-Tamaoki T: Genomic profiling of the genes on chromosome $3 p$ in sporadic clear cell renal cell carcinoma. Int J Oncol 48: 1571-1580, 2016.

6. Riquelme E, Tang M, Baez S, Diaz A, Pruyas M, Wistuba II and Corvalan A: Frequent epigenetic inactivation of chromosome $3 \mathrm{p}$ candidate tumor suppressor genes in gallbladder carcinoma. Cancer Lett 250: 100-106, 2007.

7. Kuroki T, Tajima Y, Matsuo K and Kanematsu T: Genetic alterations in gallbladder carcinoma. Surg Today 35: 101-105, 2005.

8. Penkov D, Ni R, Else C, Piñol-Roma S, Ramirez F and Tanaka S: Cloning of a human gene closely related to the genes coding for the c-myc single-strand binding proteins. Gene 243: 27-36, 2000.

9. Niki T, Galli I, Ariga H and Iguchi-Ariga SM: MSSP, a protein binding to an origin of replication in the c-myc gene, interacts with a catalytic subunit of DNA polymerase alpha and stimulates its polymerase activity. FEBS Lett 475: 209-212, 2000.

10. Niki T, Izumi S, Saëgusa Y, Taira T, Takai T, Iguchi-Ariga SM and Ariga $\mathrm{H}$ : MSSP promotes ras/myc cooperative cell transforming activity by binding to c-Myc. Genes Cells 5: 127-141, 2000.

11. Li Y, Chen L, Nie CJ, Zeng TT, Liu H, Mao X, Qin Y, Zhu YH, Fu L and Guan XY: Downregulation of RBMS3 is associated with poor prognosis in esophageal squamous cell carcinoma. Cancer Res 71: 6106-6115, 2011.

12. Wu Y, Yun D, Zhao Y, Wang Y, Sun R, Yan Q, Zhang S, Lu M, Zhang Z, Lu D and Li Y: Down regulation of RNA binding motif, single-stranded interacting protein 3 , along with up regulation of nuclear HIF1A correlates with poor prognosis in patients with gastric cancer. Oncotarget 8: 1262-1277, 2017.

13. Yang Y, Quan L and Ling Y: RBMS3 inhibits the proliferation and metastasis of breast cancer cells. Oncol Res 26: 9-15, 2018.

14. Liang YN, Liu Y, Meng Q, Li X, Wang F, Yao G, Wang L, Fu S and Tong D: RBMS3 is a tumor suppressor gene that acts as a favorable prognostic marker in lung squamous cell carcinoma. Med Oncol 32: 459, 2015.

15. Chen J, Kwong DL, Zhu CL, Chen LL, Dong SS, Zhang LY, Tian J, Qi CB, Cao TT, Wong AM, et al: RBMS3 at 3p24 inhibits nasopharyngeal carcinoma development via inhibiting cell proliferation, angiogenesis, and inducing apoptosis. PLoS One 7: e44636, 2012.

16. Livak KJ and Schmittgen TD: Analysis of relative gene expression data using real-time quantitative PCR and the 2(-Delta Delta C(T)) method. Methods 25: 402-408, 2001.

17. Fang Z, Yin S, Sun R, Zhang S, Fu M, Wu Y, Zhang T, Khaliq J and Li Y: miR-140-5p suppresses the proliferation, migration and invasion of gastric cancer by regulating YES1. Mol Cancer 16: 139, 2017.

18. Sun R, Wu J, Chen Y, Lu M, Zhang S, Lu D and Li Y: Down regulation of Thrombospondin2 predicts poor prognosis in patients with gastric cancer. Mol Cancer 13: 225, 2014.

19. Yang S, Lu M, Chen Y, Meng D, Sun R, Yun D, Zhao Z, Lu D and Li Y: Overexpression of eukaryotic elongation factor 1 alpha-2 is associated with poorer prognosis in patients with gastric cancer. J Cancer Res Clin Oncol 141: 1265-1275, 2015.

20. Meng D, Chen Y, Yun D, Zhao Y, Wang J, Xu T, Li X, Wang Y, Yuan L, Sun R, et al: High expression of N-myc (and STAT) interactor predicts poor prognosis and promotes tumor growth in human glioblastoma. Oncotarget 6: 4901-4919, 2015.

21. Weidner N, Semple JP, Welch WR and Folkman J: Tumor angiogenesis and metastasis-correlation in invasive breast carcinoma. N Engl J Med 324: 1-8, 1991.

22. Wang ZH, Li Z, Hu M, Yang QJ, Yan S, Wu RS, Li BA and Guo M: Ovol2 gene inhibits the epithelial-to-mesenchymal transition in lung adenocarcinoma by transcriptionally repressing Twist1. Gene 600: 1-8, 2017. 
23. Liu JD, Song LJ, Yan DJ, Feng YY, Zang YG and Yang Y: Caffeine inhibits the growth of glioblastomas through activating the caspase-3 signaling pathway in vitro. Eur Rev Med Pharmaco Sci 19: 3080-3088, 2015.

24. Tang L, Tan YX, Jiang BG, Pan YF, Li SX, Yang GZ, Wang M, Wang Q, Zhang J, Zhou WP, et al: The prognostic significance and therapeutic potential of hedgehog signaling in intrahepatic cholangiocellular carcinoma. Clin Cancer Res 19: 2014-2024, 2013.

25. Shen Y, Wang X, Xu J and Lu L: SerpinE2, a poor biomarker of endometrial cancer, promotes the proliferation and mobility of EC cells. Cancer Biomark 19: 271-278, 2017.

26. Wigerup C, Påhlman S and Bexell D: Therapeutic targeting of hypoxia and hypoxia-inducible factors in cancer. Pharmacol Ther 164: 152-169, 2016.

27. Zhang G, Miyake M, Lawton A, Goodison S and Rosser CJ: Matrix metalloproteinase-10 promotes tumor progression through regulation of angiogenic and apoptotic pathways in cervical tumors. BMC Cancer 14: 310, 2014.

28. Ruan K, Song G and Ouyang G: Role of hypoxia in the hallmarks of human cancer. J Cell Biochem 107: 1053-1062, 2009.
29. Okita S, Kondoh S, Shiraishi K, Kaino S, Hatano S and Okita K: Expression of vascular endothelial growth factor correlates with tumor progression in gallbladder cancer. Int J Oncol 12: 1013-1018, 1998

30. Yano S, Muguruma H, Matsumori Y, Goto H, Nakataki E, Edakuni N, Tomimoto $\mathrm{H}$, Kakiuchi S, Yamamoto A, Uehara $\mathrm{H}$, et al: Antitumor vascular strategy for controlling experimental metastatic spread of human small-cell lung cancer cells with ZD6474 in natural Killer cell-depleted severe combined immunodeficient mice. Clin Cancer Res 11: 8789-8798, 2006.

31. Davidoff AM, Ng CY, Zhang Y, Streck CJ, Mabry SJ, Barton SH, Baudino T, Zhou J, Kerbel RS, Vanin EF and Nathwani AC: Careful decoy receptor titering is required to inhibit tumor angiogenesis while avoiding adversely altering VEGF bioavailability. Mol Ther 11: 300-310, 2005.

This work is licensed under a Creative Commons

Attribution-NonCommercial-NoDerivatives 4.0 International (CC BY-NC-ND 4.0) License. 